\title{
Hubungan Antara Persepsi Mutu Pelayanan dengan Tingkat Kepuasan Pasien KIA di Puskesmas Sepaso Kecamatan Bengalon
}

\author{
Ginaya Dinda Putri ${ }^{1}$, Luvi Dian Afriyani ${ }^{2}$ \\ ${ }^{1,2}$ Program Studi Kebidanan Program Sarjana, Univeritas Ngudi Waluyo \\ Email: ginayadinda13@gmail.com, luviqanaiz@gmail.com
}

\begin{abstract}
ABSTRAK
Berbagai upaya dilakukan untuk meningkatkan mutu pelayanan puskesmas menjadi prioritas dalam pembangunan bidang kesehatan, terutama pada pelayanan KIA. Dibutuhkan kehandalan, daya tanggap, jaminan, empati dan bukti fisik dalam mutu pelayanan untuk meningkatkan kepuasan pasien KIA. Tujuan penelitian untuk mengetahui Gambaran Persepsi Mutu Pelayanan dengan Tingkat Kepuasan Pasien KIA dan adakah Hubungan Antara Persepsi Mutu Pelayanan dengan Tingkat Kepuasan Pasien KIA. Analisis data menggunakan Uji Chi Square dengan tingkat kesalahan <0,05. Jenis Penelitian ini adalah kuantitatif dengan menggunakan desain Cross Sectional. Teknik Pengambilan data menggunakan Accidental Sampling dengan menggunakan instrumen kuisoner dengan Google Form. Populasi pada penelitian ini sebanyak 50 responden. Sampel pada penelitian ini sebanyak 35 responden. Hasil Analisis Univariat Persepsi Mutu Pelayanan pasien KIA menunjukkan 15 baik (42,9\%) dan 20 kurang (57,1\%). Dan hasil Kepuasan Pasien pada Pasien KIA menunjukan baik (57,1\%) dan 15 kurang (42,9\%). Hasil Analisis Bivariat menunjukkan tidak ada hubungan antara Persepsi Mutu Pelayanan dengan Tingkat Kepuasan Pasien $(p=0,693)$. Kepuasan yang dirasakan pasien merupakan mutu pelayanan kesehatan dengan harapan pasien atau sekelompok masyarakat atau warga setempat yang telah mendapatkan apa yang diharapkan dan dibutuhkan dengan pelayanan yang diberikan oleh tenaga kesehatan. Bidan dapat meningkatkan kualitas pelayanan dengan memberikan layanan sesuai kebutuhan pasien.
\end{abstract}

\section{Kata Kunci : Persepsi, Mutu Pelayanan, Kepuasan Pasien KIA}

\begin{abstract}
Relationship Between Perception Of Service Quality With Kia Patients Satisfaction In Public Health Center Sepaso Kecamatan Bengalon

Various efforts to improve the quality of puskesmas services a priority in the development of the health sector, especially MCH services. Reliability, responsiveness, assurance, empathy and physical evidence of service quality are needed to improve patient satisfaction. Research to find out the Perception of Service Quality with the Satisfaction Level of MCH Patients and is there a correlation between Perceptions of Service Quality and the Satisfaction Level of KIA Patients. Data analysis used the Chi Square Test with an error rate of $<0.05$ This type of research is quantitative using a cross sectional design. Data collection techniques using accidental sampling using a questionnaire instrument via Whatss App Group and Google Form. The population in this study were 50 respondents. The sample in this study were 35 respondents. The results of the Univariate Analysis of Service Quality Perception of KIA patients showed that 15 were good
\end{abstract}

Hubungan Antara Persepsi... Ginaya Dinda Putri, Luvi Dian Afriyani Journal of Holistics and Health Sciences Vol. 3, No. 2 September 2021 
(42.9\%) and 20 were poor (57.1\%). In the Reliability Dimension 20 good (57.1 Satisfaction $(p=0.693)$. The satisfaction felt by patients is the difference in the quality of health services with the expectations of the patient or a group of people or local residents who have got what is expected and needed with the services provided by health workers. Midwives can improve service quality by providing services according to patient needs.

\section{Key Words : Perception, Service Quality, Patient Satisfaction KIA}

\section{PENDAHULUAN}

Puskesmas merupakan fasilitas kesehatan yang sangat sering digunakan warga maupun masyarakat untuk memperoleh pelayanan kesehatan yang sesuai kebutuhan keinginan dan memadai untuk kondisi pasien juga mampu memberikan atau memenuhi pelayan yang baik dan kooperatif. Sebagaimana peran Puskesmas adalah sebagai fasilitas kesehatan yang mampu memberikan pelayanan kesehetan primer serta pelayanan kesehatan promotif dan juga preventif, mampu menempatkan dan memberikan peranan yang sangat bermanfaat dalam sistem pelayanan kesehatan. ruang lingkup kesehatan. Pemberian layanan kesehatan mengkaitkan layanan kesehatan yan bermutu dengan tersedianya alat yang memadai, Standar Operasional Prosedur, standar pelayanan profesi di setiap melaksanakan pelayanan kesehatan sesuai dengan teknologi kesehatan yang tepat dan memumpuni, serta hasi dari pelayanan itu sendiri (outcome). Adanya pelayanan yang bermutu dapat memberikan keoptimisan pasien di masa pemulihan dan kesehatan menjadi suatu keuntungan pada fasilitas kesehatan dalam kualitas pelayanan kesehatan di pandangan masyarakat. Maka hal ini telah ditentukan melalui profesi tenaga kesehatan, yang di inginkan serta dibutuhkan oleh pasien atau masyarakat juga mampu dijangkau oleh pasien, masyarakat atau warga setempat. (Muninjaya, 2011).

Kepuasan pasien adalah keluaran (outcome) dari layanan kesehatan dan satu perubahan dari sistem layanan kesehatan yang ingin dilakukan serta merupakan tujuan akhir dari pemasaran suatau rumah sakit. Kepuasan pasien akan tercapai apabila diperoleh hasil optimal bagi setiap pasien dan pelayanan kesehatan memperhatikan kemampuan pasien atau keluarganya, adanya perhatian terhadap keluhan , kondisi fisik dan tanggapan atau memprioritaskan kebutuhan pasien ( Tjipyono(2011) dalam Noviyanti (2020))

Mutu Pelayanan (Service quality) sangat tergantung pada tiga hal, yaitu sistem, teknologi dan manuaia. Faktor manusia memegang kontribusi terbesar sehingga mutu layanan lebih sulit ditiru dibandingkan dengan mutu produk dan harga. Salah satu konsep mutu layanan yang popular adalah ServQual. Berdasarkan konsep muti ini, mutu atau kualitas layanan diyakini memiliki 5 dimensi yaitu reliability, responsiveness, assurance, emphaty dan tangible (Candrianto,2021).

Pelayanan kebidanan merupakan tugas yang menjadi tanggung jawab dari profesi bidan dalam sistem pelayanan kesehatan yang bertujuan untuk meningkatkan kesehatan ibu dan anak dalam rangka mewujudkan mkesehatan keluarga dan masyarakat 
sesuai dengan standar pelayanan kebidanan. Mutu pelayanan kebidanan adalah bentuk pelayanan kebidanan terbaik yang memnuhi atau melebihi kebutuhan dan harapan pelanggan/pasien sesuai dengan standard an kode etik profesi yang telah ditetapkan melalui peningkatan yang berkelanjutan atas semua proses (Astari RY,2020)

Para petugas kesehatan terutama bidan mendapat kebijakan untuk meningkatkan kepuasan pasien pada pemeriksaan KIA ( Kesehetan Ibu dan Anak ) yang menjadi sorotan tentang bagaimana kunjungan ibu hamil, persalinan, Nifas, Imunisasi, dan KB untuk memeriksakan kondisi dan melakukan kunjungan ulang. Fasilitas kesehatan baik primer maupun rujukan harus betul-betul siap dalam sarana prasarana maupun SDM. Keselamatan bidan dan pasien harus lebih diutamakan dan diperlukan penyesuaian pelayanan agar terhindar dari penularan, dan akses pelayanan mengalami perubahan baik puskesmas maupun fasilitas kesehatan rujukan membatasi pelayanan.Tujuan penelitian yaitu untuk mengetahui hubungan antara persepsi mutu pelayanan dengan tingkat kepuasan pasien KIA di Puskesmas Sepaso Kecamatan Bengalon

\section{METODE}

Penelitian ini dilaksanakan di Puskesmas Sepaso Kecamatan Bengalon, Kabupaten Kutai Timur, Provinsi Kalimantan Timur pada tanggal 14 Desemeber 2020 sampai dengan 6 Januari 2021 menggunakan desain penelitian Deskriptif Kuantitatif dengan pendektan Accidental Sampling, Teknik pengumpulan data menggunakan data primer dan data sekunder, serta melalui kuisoner via Whats App Group dan Google Form, dan dengan Teknik Analisa Univariat dan Bivariat. Populasi pada penelitian ini adalah 250 pasien KIA pada bulan Mei sampai dengan September, Sampel dalam penelitian ini berjumlah 35 pasien KIA. Pengolahan data menggunakan teknik statistik, yaitu dengan menggunakan uji chi square

\section{HASIL DAN PEMBAHASAN \\ Hasil}

Tabel 1 Tabel Karakteristik Responden

\begin{tabular}{lcc}
\hline \multicolumn{1}{c}{ Karakteristik Responden } & Frekuensi (n) & Persentase (\%) \\
\hline Jenis Kelamin & 0 & 0 \\
Laki-laki & 35 & 100,0 \\
Perempuan & & \\
\hline Umur & 12 & 34,3 \\
$<20$ & 14 & 40,0 \\
$21-35$ & 9 & 25,7 \\
$>35$ & & \\
\hline Pendidikan & 9 & 25,7 \\
Dasar & 18 & 51,4 \\
Menengah & 8 & 22,9 \\
Tinggi & $\mathbf{3 5}$ & $\mathbf{1 0 0 , 0}$ \\
\hline Total & & \\
\hline
\end{tabular}


Berdasarkan Tabel 1 bahwa dari 35 responden hanya terdapat 35 jenis kelamin perempuan. Kemudian pada Karakteristik Umur terdapat 12 pasien dengan rentan umur $<20$ tahun, 14 pasien dengan umur 21-35 tahun, dan 4 pasien dengan rentan umur >35 tahun. Karateristik pendidikan terdapat 9 pasien rata-rata lulusan pendidikan Dasar, 18 pasien dengan rata-rata lulusan Pendidikan Menengah, 8 pasien dengan rata- rata lulusan Pendidikan Tinggi

Tabel 2 Gambaran Persepsi Mutu Pelayanan Pasien KIA Puskesmas Sepaso Kecamatan Bengalon

\begin{tabular}{|c|c|c|}
\hline Persepsi Mutu Pelayanan & Jumlah & Persentase (\%) \\
\hline Baik & 15 & 42,9 \\
\hline Kurang & 20 & 57,1 \\
\hline Total & 35 & $\mathbf{1 0 0 , 0}$ \\
\hline
\end{tabular}

Berdasarkan Tabel 2 dapat diketahui bahwa dari 35 responden didapatkan hasil penelitian sebagian besar $15(42,9 \%)$ memiliki Persepi
Mutu Pelayanan baik, dan $20(57,1 \%)$ menyatakan Persepsi Mutu Pelayanan kurang.

Tabel 3 Gambaran Tingkat Kepuasan Pasien KIA Puskesmas Sepaso Kecamatan Bengalon

\begin{tabular}{lccc}
\hline & Kepuasan Pasien KIA & Jumlah & Persentase (\%) \\
\hline Baik & 20 & 57,1 \\
Kurang & 15 & 42,9 \\
\hline Total & $\mathbf{3 5}$ & $\mathbf{1 0 0 , 0}$ \\
\hline
\end{tabular}

Berdasarkan Tabel 3 dapat diketahui bahwa dari 35 responden didapatkan hasil penelitian sebagian besar $20(57,1 \%)$ memiliki Tingkat
Kepuasan Pasien KIA baik, dan 15 $(42,9 \%)$ menyatakan Tingkat Kepuasan Pasien KIA kurang.

Tabel 4 Tabulasi Silang Hubungan Antara Persepsi Mutu Layanan dengan Tingkat Kepuasan Pasien KIA Puskesmas Sepaso

\begin{tabular}{|c|c|c|c|c|c|c|c|}
\hline \multirow{3}{*}{$\begin{array}{c}\text { Persepsi Mutu } \\
\text { Pelayanan }\end{array}$} & \multicolumn{6}{|c|}{ Kepuasan Pasien } & \multirow{2}{*}{$\begin{array}{c}P \\
\text { value }\end{array}$} \\
\hline & \multicolumn{2}{|c|}{ Puas } & \multicolumn{2}{|c|}{ Tidak Puas } & \multicolumn{2}{|c|}{ Total } & \\
\hline & $\mathrm{N}$ & $\%$ & $\mathrm{~N}$ & $\%$ & $\mathrm{~N}$ & $\%$ & \\
\hline Baik & 8 & 53,3 & 7 & 46,7 & 15 & 100,0 & $p 0,693$ \\
\hline Kurang & 12 & 60,0 & 8 & 40 & 20 & 100,0 & \\
\hline Total & & & & 35 & & 100 & \\
\hline
\end{tabular}

Berdasarkan tabel 4 Persepsi Mutu Pelayanan baik lebih didapatkan bahwa responden dengan banyak menyatakan kepuasan yaitu 8 
orang $(53,3 \%)$ dibandingkan dengan yang tidak puas sebanyak 7 orang $(46,7 \%)$. Namun responden dengan Persepi Mutu Pelayanan kurang lebih banyak juga yang menyatakan puas sebanyak 12 orang $(60,0 \%)$ dibandingkan yang tidak puas 8 orang (40,0\%). Berdasarkan Hasil Uji Chi Square sebesar 0,693 atau >0,05 maka Ho diterima dan Ha ditolak. Maka tidak ada hubungan antara Persepsi Mutu Pelayanan dengan Tingkat Kepuasan Pasien KIA di Puskesmas Sepaso Kecamatan Bengalon

\section{PEMBAHASAN}

Persepsi mutu pelayanan tentang dimensi kehandalan, daya tanggap, jaminan, empati dan bukti langsung yang diberikan tenaga kesehatan oleh pasien KIA menujukkan hasil baik ( 42,9\%). Menurut Putri S I dan Yunita A (2021) Pasien/masyarakat akan melihat layanan kesehatan yang bermutu adalah layanan yang dapat memenuhi kebutuhan yang dirasakan dan diselenggarakan dengan cara yang sopan dan santun, tepat waktu, tanggap serta mampu menyembuhkan keluhan serta mencegah berkembangnya atau meluasnya penyakit. Pandangan pasien ini sangat panting karena pasien yang merasa puas akan mematuhi pengobatan dan mau melakukan kunjungan kembali. Pemberi layanan harus memahami status kesehatan dan kebuthan layanan kesehatan masyarakat yang dilayaninya dan mendidik serta melibatkan masyarakat dalam menentukan bagaimana cara yang paling efektif menyelenggarakan layanan kesehan sehingga diperlukan hubungan saling percaya antara pemberi layanan kesehatan dengan pasien atau masyarakat.

\begin{tabular}{|c|c|}
\hline Pada & Persepsi \\
\hline Pelayanan $\mathrm{k}$ & kurang $(57,1 \%)$ \\
\hline kurangnya & komunikasi \\
\hline
\end{tabular}
pasien. Berdasarkan hasil penelitian Toliaso (2018) yang menyatakan bahwa Dari hasil wawancara yang dilakukan peneliti banyak pasien mengatakan setiap kali mendapatkan pelayanan bidan maupun tenaga kesehatan lainnya selalu memberikan penjelasan mengenai pengobatan yang dilakukan mulai dari hal yang harus dipatuhi dalam pengobatan pasien, tindakan-tindakan yang dilakukan bidan sesuai dengan keluhan yang dialami oleh pasien.

\begin{tabular}{llr}
\multicolumn{1}{c}{ Dari } & hasil penelitian \\
didapatkan & penilaian & pasien \\
menyatakan & baik pada & Mutu
\end{tabular} pelayanan dimensi Bukti Fisik lebih banyak dibanding pasien yang menyatakan Mutu pelayanan dimensi Bukti Fisik kurang. Sesuai dengan penelitian Susmaneli H dan Triana A (2014) bahwa responden dengan dimensi mutu bukti langsung buruk beresiko 14 kali untuk tidak puas terhadap pelayanan program Jampersal di RSUD Kabupaten Rokan Hulu dibandingkan dengan responden yang memiliki dimensi mutu bukti langsung yang baik. Berdasarkan hasil tersebut menunjukkan bahwa semakin tidak baik persepsi pasien tentang bukti langsung maka responden akan semakin tidak puas terhadap layanan kebidanan yang diberikan . Tanggapan positif sebagian besar pasien merasa nyaman melakukan pemeriksaan dan kunjungan di Puskesmas Sepaso. Perlu upaya meningkatan secara terus menerus agar bukti langsung berupa sarana dan prasaran dapat dirasakan manfaat dan kenyamanannya bagi pasien. 
Pasien KIA yang menyatakan Kepuasan baik $(57,1 \%)$. Masih ada pasien KIA yang menyatakan kurang (42,9\%) menyatakan bahwa masih ada beberapa hal yang harus diperhatikan seperti menyampaikan informasi yang dibutuhkan pasien, memahami keluhan pasien, cara menyampaikan penjelasan yang rinci, keramahan dari petugas kesehatan, serta kenyamanan fasilitas ruangan bagi pasien KIA. Iryadi Roni (2020) dimana hasil penelitian dapat diketahui bahwa sebagian besar responden memberikan penilaian baik terhadap kualitas pelayanan bidan yaitu sebanyak 28 responden $(65,1 \%)$. Berdasarkan hasil penelitian dapat diketahui bahwa lebih dari setengah responden memiliki tingkat kepuasan puas yaitu sebanyak 29 responden $(67,4 \%)$. Terdapat pengaruh kualitas pelayanan bidan terhadap kepuasan pasien KIA di Puskesmas Pangenan Kabupaten Cirebon dengan nilai p-value sebesar 0,0001 dimana lebih kecil dari nilai $\alpha$ $(0,05)$. Sejalan dengan penelitian ini menunjukkan bahwa ada hubungan antara persepsi bukti langsung dengan tingkat kepuasan, ada hubungan persepsi kehandalan dengan tingkat kepuasan. Sedangkan yang tidak berhubungan dengan tingkat kepuasan pasien adalah persepsi daya tanggap, persepsi jaminan dan persepsi perhatian.

\section{SIMPULAN}

Gambaran Persepsi Mutu Pelayanan Pasien KIA Puskesmas Sepaso Kecamatan Bengalon dapat disimpulkan dari hasil penelitian bahwa pada Persepsi Mutu pelayanan 15 baik $(42,9 \%)$ dan 20 kurang (57,1\%). Gambaran Kepuasan Pasien KIA Puskesmas Sepaso Kecamatan Bengalon dapat disimpulkan dari hasil penelitian bawa pada gambaran Kepuasan Pasien baik $(57,1 \%)$ dan 15 kurang $(42,9 \%)$.Tidak Ada Hubungan Persepsi Mutu Pelayanan dengan Tingkat Kepuasaan Pasien KIA Puskesmas Sepaso Kecamatan Bengalon didapatkan hasil penelitian dengan Uji Chi Square dengan tingkat kesalahan 0,05. Dapat disimpulkan dari hasil penelitian bahwa Tidak ada hubungan antara Persepsi Mutu Pelayanan dengan Tingkat Kepuasan Pasien $(p=0,693)$.

\section{UCAPAN TERIMA KASIH}

Ucapan terima kasih kami ucapkan kepada Puskesmas Sepaso Kecamatan Bengalon dan kepada Universitas Ngudi Waluyo.

\section{DAFTAR PUSTAKA}

Astari Ruri Yuni.(2020). Mutu Pelayanan Kebidanan dan Kebijakan Kesehatan. Deepublish:Yogyakarta

Astuti, Dwi (2017). Persepsi Pasien tentang mutu Pelayanan Dengan Tingkat Kepuasan PAsien Rawat Inap Puskesmas. HIGEIA Journal O Public Health Research and Development. Vol 1 (3).

Candrianto (2021). Kepuasan Pelanggan Suatu Pengantar. Literasi Nusantara Abadi: Malang

Iryadi Roni (2020). Pengaruh Kualitas Pelayahan Bidan Terhadap Kepuasan Pasien Kia di Puskesmas Pengenan Kabupaten Cirebon. Jurnal Cahaya Mandalika. Vol 1 (3). Hal 60-65 


\section{Muninjaya Gde A.A.(2011). Manajemen Mutu Pelayanan Kesehatan .EGC:Jakarta \\ Noviyanti (2020).Faktor Pelayanan Yang Profesional Terhadp Kepuasan Pasien.Qiara Medika:Jawa Timur}

Putri SI dan Yunita A (2021). Buku Saku Mutu Layanan Kebidanan. Graf Literasi
Susmaneli H dan Triana A.(2014). Dimensi Mutu Pelayanan Kebidanan terhadap Kepuasan PAsien Program Jampersal. Jurnal Kesmas. Vol 8(8).Hal 418- 422

Toliaso (2018). Hubungan Mutu Pelayanan Kesehatan dengan Kepuasan Pasien di Puskesmas Bahu Kota Manado. Jurnal KESMAS.Vol 7 (4). 